M. Phil

Screening existing black pepper (Piper nigrum L. Family Piperaceae) cultivars for superior spice value (high essential oil, oleoresin and piperine content) and their in vitro propagation

by

R. M. Dharmadasa 
The work described in this thesis was carried out by me under the supervision of Dr. Y.M.H.B. Yapabandara (Industrial Technology Institute) and Dr. (Mrs). P.L Hettiarachchi (University of Sri Jayawardanapura) and a report on this has not been submitted in whole or in part to any University for another degree.

02.1 .2 .20 .0 .2

Date

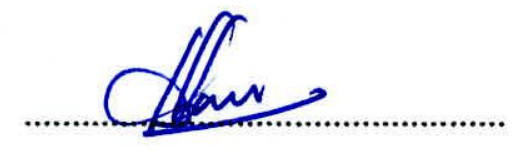

Signature

(R.M. Dharmadasa) 
We certify that the above statement made by the candidate is true and that this thesis is suitable for submission to the University for the purpose of evaluation

$02-12-2002$

Date

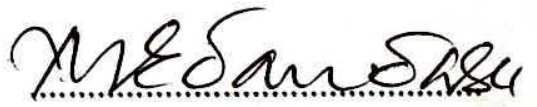

Dr. Y.M.H.B. Yapabandara

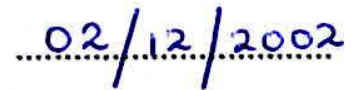

Date

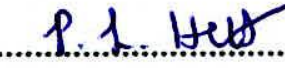 \\ Dr. (Mrs) P.L. Hettiarachchi
}


Screening existing black pepper (Piper nigrum L. Family

Piperaceae) cultivars for superior spice value (high essential oil, oleoresin and piperine content) and their in vitro propagation

by

Rathnayake Mudiyanselage Dharmadasa

Thesis submitted to the University of Sri Jayawardanepura for the award of the degree of Master of Philosophy in Applied sciences on $2^{\text {nd }}$ December 2002 


\section{KEY TO ABBREVIATIONS}

\begin{tabular}{|c|c|}
\hline $\mathrm{AC}$ & : Activated charcoal. \\
\hline ANOVA & : Analysis of Variance \\
\hline BA & : 6-Benzylaminopurine ( $\mathrm{N}^{6}$ Benzyladenine) \\
\hline${ }^{\circ} \mathrm{C}$ & : Degree of Centigrade \\
\hline CRD & : Completely Randomized Design \\
\hline DEA & : Department of Export Agriculture \\
\hline GLC & : Gas Liquid Chromatography \\
\hline GLM & : Generalized Linear Model \\
\hline $\mathrm{Ha}$ & : Hectare \\
\hline HPLC & : High Performance Liquid Chromatography \\
\hline IAA & : 3-Indoleacetic acid. \\
\hline IBA & : 3-Indolebutyric acid \\
\hline $\mathrm{Kn}$. & : Kinetin \\
\hline MS & : Murasige and Skoog's (1962) medium \\
\hline NAA & : 1-Naphtalene Acetic acid \\
\hline PVP & : Polyvinylpyrelidone \\
\hline SAS & : Statistical Analysis System \\
\hline SDC & : Sodium diethyldithiocarbonate \\
\hline 2,4-D & : 2,4-Diclorophenoxy Acetic Acid. \\
\hline $2 \mathrm{iP}$ & : 2-Isopentenyl adenine \\
\hline
\end{tabular}




\section{TABLE OF CONTENT}

\subsection{INTRODUCTION}

\subsection{LITERATURE REVIEW}

2.1. Physical yield parameters 5

2.2 Chemical Analysis 6

2.2. 1 Distillation and quantification of pepper oils 6

2.2.2. Parameters indicating chemical quality of black pepper (Piper nigrum L) 6

2.2.3. Essential oil 7

2.2.4 Composition of pepper oil. 8

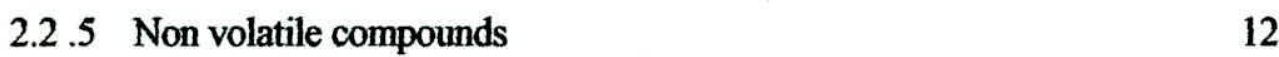

2.2.6 Isolation and quantification of non-volatile 13 compounds

2.2.7 Determination of piperine content of black pepper 14

$\begin{array}{ll}\text { 2.3. Plant Tissue Culture } & 16\end{array}$

2.3.1 Botany of the Plant 16

$\begin{array}{ll}\text { 2.3.2 In vitro propagation of plants } & 16\end{array}$

$\begin{array}{lll}\text { 2.3.3 Methods of in vitro clonal propagation } & 18\end{array}$

2.3.3.1 Regeneration via somatic embryos

(Somatic embryogenesis) $\quad 18$

2.3.3.2 Regeneration via adventitious meristems (Organogenesis) 18

$\begin{array}{lll}\text { 2.3.3.3 } & \text { Axillary bud proliferation } & 19\end{array}$

2.3.4 Different culture methods used in tissue culture 20

$\begin{array}{lll}\text { 2.3.4.1 Shoot tip culture } & 20\end{array}$

$\begin{array}{lll}2.3 .4 .2 & \text { Bud and nodal culture } & 20\end{array}$ 
$\begin{array}{ll}2.3 .5 & \text { Stages in in vitro } \text { propagation } \\ \end{array}$

2.3.5.1 Stage 0. Maintenance of mother plants 21

2.3.5.2 Stage 1 Establishment of aseptic cultures $\quad 21$

$\begin{array}{lll}\text { 2.3.5.2.1 Culture media } & 23\end{array}$

$\begin{array}{lll}\text { 2.3.5.2:2 Growth regulators } & 24\end{array}$

$\begin{array}{ll}\text { 2.3.5.2.3 Incubation conditions } & 25\end{array}$

$\begin{array}{lll}\text { 2.3.5.2.4 Polyphenol oxidation } & 25\end{array}$

2.3.5.3 Stage II. Shoot multiplication 28

2.3.5.3.1 Growth regulators 28

2.3.5.3.2 Shoot multiplication of Piper species 29

2.3.5.4 Stage III Rooting of in vitro regenerated pepper plants $\quad 30$

2.3.5.5 Acclimatization of in vitro propagated shoots 31

2.3.6 Callus establishment of black pepper 33

$\begin{array}{ll}\text { 3.0 MATERIALS AND METHODS } & 35\end{array}$

3.1 Selection of mother vines from different locations 35

3.2 Comparison of yield parameters of local cultivars with introductions 38

3.3 Determination of moisture content and chemical analysis of

pepper berries

$\begin{array}{lll}\text { 3.3.1 Moisture content } & 39\end{array}$

3.3.1.1 Toluene distillation method 39

3.3.1.2 Moisture balance method 39

3.3.2 Chemical characteristics of pepper samples collected from different districts 
3.3.3 Comparison of chemical composition of essential oil using Gas Liquid Chromatography (GLC).

3.3.4 Comparison of oleoresin content of selected mother vines from different pepper growing areas.

3.3.5 Determination of piperine content by direct UV method and High Performance Liquid Chromatography (HPLC)

3.3.5.1 Preparation of standard piperine solution

3.3.5.2 High Performance Liquid Chromatography

3.3.5.3 Determination of piperine content by direct UV

Spectrophotometer method

3.4.1.General Procedure

3.4.1.1 Collection and Maintenance of mother plants

3.4.1.2 Stock solutions and basal medium

3.4.1.3.1. Preparation of stock solutions of growth regulators

3.4.1.3.2. Preparation of culture media

3.4.1.3.3. Explants preparation and sterilization

3.4.1.3.4. Building up of stock cultures for experiments

3.4.1.8 Experimental design and statistical analysis $\quad 47$ 
3.4.2.1 Comparison of contamination between explants

of greenhouse and field grown mother plants

3.4.2.2 Comparison of shoot multiplication of nodal explants

in MS medium supplemented with five different

concentrations of BA.

3.4.2.3 Comparison of shoot multiplication of nodal explants

in MS medium supplemented with five different

concentrations of Kinetin (Kn).

3.4.2.4 Comparison of shoots multiplication of nodal explants in

MS medium supplemented with five different

concentrations of $2 \mathrm{ip}$.

3.4.2.5 Comparison of shoot multiplication of black pepper in

different BA levels $(0,1,3.5,5,7.5,10,20,30,40,50 \mathrm{mg} / \mathrm{l})$.

3.4.2.6 Comparison of shoot multiplication of five different pepper cultivars in solid and liquid media

3.4.2.7 Comparison of shoot multiplication of black pepper nodal explants in different concentrations of BA $(0,1,2.5,3.5$ and $5 \mathrm{mg} / \mathrm{l})$ and NAA $(0,0.1$ and $0.2 \mathrm{mg} / \mathrm{l})$

3.4.2.8 Comparison of rooting of in vitro generated black pepper shoots in MS medium supplemented with Charcoal and IBA.

3.4.2.9 Acclimatisation of in vitro propagated plantlets

3.4.2.10 Callus establishment from leaf explants in MS medium supplemented with different concentrations of 2,4-D and $\mathrm{BA}$ in dark and light conditions. 
3.4.2.11 Callus establishment from stem explants (internode) of black pepper in half strength MS medium supplemented with different concentrations of IAA and BA.

4. O RESULTS 55

4.1 Comparison of yield parameters of local cultivars with introductions 55

4.1.1. Moisture content 56

4.2 Chemical analysis $\quad 56$

4.2.1 Chemical characteristics of pepper samples collected from different districts.

4.2.2 Comparison of pepper oil content of samples collected from different areas.

4.2.3. Comparison of chemical composition of essential oil using Gas Liqiud Chromatography (GLC)

4.2.4 Comparison of oleoresin content of selected mother vines from different pepper growing areas.

4.2.5 Determination of piperine content by direct UV method and High Performance Liquid Chromatography (HPLC).

4.3.1 Comparison of contamination between explants of greenhouse and field grown mother plants.

4.3.2 Comparison of shoots multiplication of nodal explants in MS medium supplemented with five different concentrations of BA 75

4.3.3 Comparison of shoot multiplication of black pepper nodal explants in MS medium supplemented with 5 concentrations of $\mathrm{Kn}$ and $3.5 \mathrm{mg} / \mathrm{l} \mathrm{BA}$. 
4.3.4 Comparison of shoots multiplication of nodal explants in MS medium supplemented with 5 different concentrations of 2 ip and $3.5 \mathrm{mg} / 1 \mathrm{BA} . \quad 79$

4.3.5 Comparison of shoot multiplication of black pepper nodal explants in MS medium supplemented with in different BA levels $(0,1,3.5,5,7.5,10,20,30,40,50 \mathrm{mg} / \mathrm{l})$.

4.3.6 Comparison of shoot multiplication of five different pepper cultivars in solid and liquid media

4.3.7 Comparison of shoot multiplication of black pepper nodal explants in different concentrations of BA $(0,1,2.5,3.5$ and $5 \mathrm{mg} / \mathrm{l})$ and NAA $(0,0.1$ and $0.2 \mathrm{mg} / \mathrm{l})$

4.3.8 Comparison of rooting of in vitro generated pepper shoots in MS medium supplemented with charcoal and IBA. $\quad 91$

4.3.9 Acclimatization of in vitro propagated plantlets in soil. 97

4.3.10 Callus establishment from leaf explants in MS medium supplemented with different concentrations of 2,4-D and BA in dark and light conditions

4.3.11 Callus establishment from stem explants (internode) of black pepper in half strength MS medium supplemented with different concentration $\mathrm{s}$ of IAA and BA

$\begin{array}{lll}5.1 & \text { Physical properties } & 110\end{array}$

$\begin{array}{lll}5.2 & \text { chemical analysis } & 111\end{array}$

$\begin{array}{lll}5.3 & \text { Plant tissue culture } & 115\end{array}$

6.0 CONCLUSIONS, SUGGESTIONS AND FUTURE RECOMMENDATIONS 


\section{LIST OF TABLES}

Table 2. 1 Some volatile components present in black pepper oil

(Wrolted and Jenning, 1965)

Table 2.2 Composition of Sri Lankan black pepper oil as reported earlier

Table 2.3 Composition of pepper oil in some lines selected by DEA

(Samuel, 1984).

Table 2.4 Composition of black pepper oil reported by previous workers

Table 3.1 Identity, Location and districts of selected mother vines

Table 3.2 Preparation of stock solutions of growth regulators

Table 3.3 Names and the origin of the pepper cultivars used for experiments

Table 4.1.1 Summary of mean yield parameters of local pepper lines and

Introductions (Panniyur and Kuchin)

Table 4.2.1 Moisture content and chemical characteristics of pepper samples selected from Kandy district.

Table 4.2.2 Moisture content and chemical characteristics of pepper samples selected from Monaragala district.

Table 4.2.3 Moisture content and chemical characteristics of pepper samples selected from Matale district.

Table 4.2.4 Moisture content and chemical characteristics of pepper samples selected from Matara district.

Table 4.2.5 Chemical characteristics of pepper samples selected from Nuwaraeliya district.

Table 4.2.6 Moisture content and chemical characteristics of pepper samples selected from Gampaha district.

Table 4.2.7 Moisture content and chemical characteristics of pepper samples selected from Department of Export Agriculture selections.

Table 4.2.8. Moisture content and chemical characteristics of pepper introductions (Panniyur and Kuchin) grown in different locations. 
Table 4.2.9 Pepper oil content (Range and average value) of several pepper cultivars $\begin{array}{ll}\text { growing in different districts. } & 61\end{array}$

Table 4.2.10. Chemical characteristics and locations of high oil content mother vines. 62

Table 4.2.11 Major compounds of pepper oil with averages and ranges 66

Table 4.2.12 Results of the GLC analysis of pepper oil 67

Table 4.2.13 Total Oleoresin content (\%) in different pepper cultivars / selections.

Table 4.2.14 Summary of the piperine content in different local pepper samples and Introductions detected using direct UV and HPLC methods.

Table 4.2.15. The average values of different black pepper cultivars with their standard deviations

Table 4.3.1 Percentages of contaminated, dead and uncontaminated cultures of field and greenhouse grown plants.

Table 4.3.2 Effect of different levels of BA on number of shoots (SHNM), elongation of shoots (SHEL), number of leaves (LFNM) and overall growth score (SCORE) six weeks after culture establishment.

Table 4.3.3 Effect of different Kn levels on number of shoots (SHNM), shoot elongation (SHEL), number of leaves (LFNM) and overall growth score. 79

Table 4.3.4 Effect of different 2iP levels on number of shoots (SHNM), shoot length (SHEL), number of leaves (LFNM) and overall growth score after 6 weeks.

Table 4.3.5 Number of shoots (SHNM), shoot elongation (SHEL), number of leaves (LFNM) and score on overall growth of cultivars in different levels of BA after 6 weeks.

Table 4.3.6 Number of shoots produced by 5 different cultivars cultured in liquid and solid medium.

Table 4.3.7 Shoot elongation ( $\mathrm{cm}$ ) of 5 cultivars cultured in liquid and solid media. 85

Table 4.3.8 Number of leaves of 5 cultivars cultured in liquid and solid media. $\quad 86$

Table 4.3.9 Growth score of 5 cultivars cultured in liquid and solid media 
Table 4.3.10 Effect of different concentrations and combinations of BA and NAA on number of shoots After 6 weeks.

Table 4.3.11 Combined effect of different concentrations of NAA and BA on shoot Elongation (cm)

Table 4.3.12 Effect of different concentrations and combinations of NAA and BA on number of emerging leaves

Table 4.3.13 Effect of different concentrations and combinations of BA and NAA on overall growth score

Table 4.3.14 The effect of IBA with or without activated charcoal (AC) on number of roots of black pepper after 6 weeks.

Table 4.3.15 The effect of IBA with or without activated charcoal (AC) on root length (RTLG) of black pepper expressed as number of shoots after 6 weeks.

Table 4.3.16 The effect of IBA with or without activated charcoal (AC) on number of leaves of black pepper (number of leaves (LFNM) after 6 weeks). 93

Table 4.3.17 The effect of IBA and activated charcoal (AC) on number of shoots (SHNM) of black pepper (expressed as number of shoots after 6 weeks) 94

Table 4.3.18 The effect of IBA with or without activated charcoal (AC) on shoot elongation of black pepper after 6 weeks.

Table 4.3.19 The effect of IBA with or without activated charcoal (AC) on growth score of black pepper after 6 weeks.

Table 4.3.20 . Survival percentage of pepper plants during acclimatization up to 8 weeks.

Table 4.3.21 Effect of IBA and activated charcoal on shoot number during acclimatization of black pepper.

Table4.3.22 Effect of IBA and activated charcoal on shoot elongation (SHEL) on acclimatization of Black pepper.

Table 4.3.23 Effect of IBA and activated charcoal on number of leaves produced during acclimatization of Black pepper. 
Table 4.3.24 Effect of IBA and activated charcoal on growth score during acclimatization of Black pepper

Table 4.3.25 Growth performances of black pepper plants, which were rooted in different IBA and charcoal levels after 8 weeks of acclimatization expressed as number of shoots (SHNM), shoot elongation (SHEL), number of leaves (LFNM) and overall growth score (SCORE).

(Summary of Table 4.3.21 - 4.3.24)

Table 4.3.26 Percentage of callus formation different concentrations of BA and 2,4-D in continues light condition

Table 4.3.27 Effect of different concentrations of BA and 2,4-D in dark condition

Table 4.3.28. Callus establishment of stem explants of black pepper in half strength MS medium supplemented with different concentrations of IAA and BA. 


\section{LIST OF FIGURES}

Figure: 2.1 Piperine (2, trans 4, trans) $\left(\mathrm{C}_{17} \mathrm{H}_{19} \mathrm{O}_{3} \mathrm{~N}\right) \quad 14$

Figure 4.2.1 Oil content of local and introduced cultivars 61

Figure 4.2.2. Percentage of six major components present in local selections 63

Figure 4.2.3. Percentage of six major components present in DEA selections 63

Figure 4.2.4. Percentage of six major components present in in Panniyur 64

Figure 4.2.5. Percentage of six major components present in Kuchin 64

Figure 4.2.6. Oleoresin content of different pepper cultivars/lines 70

Figure 4.2.7. Piperine content of different pepper cultivars/lines 71 


\section{LIST OF PLATES}

Plate 4.3.1 Black pepper nodal explant established in MS medium

Plate 4.3.2 Shoot multiplication of nodal explants established in MS medium supplemented with 5 concentrations of BA ( left to right $0,2.5,3.5$ and $5 \mathrm{mg} / \mathrm{l} \mathrm{BA}$.

Plate 4.3.3. Growth of nodal explants established in MS medium supplemented with 5 concentrations of $2 \mathrm{ip}$ ( from left to right $0,1,2.5,3.5,5$ and $3.5 \mathrm{mg} / \mathrm{BA})$.

Plate 4.3.4. Shoot multiplication of nodal explants in MS medium supplemented with $10 \mathrm{BA}$ concentrations ( from left to right $0,1,3.5,5,7.5,10,20,30$, 40 and $50 \mathrm{mg} / \mathrm{l})$

82

Plate 4.35 Black pepper shoots growing in solid and liquid media (left to right solid and liquid media)

Plate 4.3.6 Black pepper shoots showing better multiplication in liquid medium in cultivar M4 after 6 weeks.

Plate 4.3.7 Overall growth performance of in vitro generated black pepper shoots in MS medium supplemented with IBA and activated charcoal (from left to right control, $1 \mathrm{mg} / 1 \mathrm{IBA}, 1 \mathrm{mg} / 1 \mathrm{IBA}$ and $0.2 \% \mathrm{AC}, \mathrm{AC}$ only).

Plate 4.3.8 Black pepper shoots showing roots induced in MS medium containing $1 \mathrm{mg} / 1$ IBA

Plate 4.3.9 In vitro regenerated black pepper plants acclimatized in a growth Chamber. 
Plate 4.3.10 Black pepper plants rooted in different IBA and AC levels after transferring to potting mixture (coir: sand: compost 1:1:1) with after 8 weeks acclimatization ( left to right control, AC only, IBA only and AC \& IBA).

Plate 4.3.11 Plants rooted in IBA and AC with control (Left to right control and $0.2 \% \mathrm{AC}+1 \mathrm{mg} / 1 \mathrm{IBA})$.

Plate 4.3.12 In vitro regenerated pepper plants growing in cement pots containing soil (after 5 months).

Plate 4.3.13 Callus produced from leaf explants of black pepper in MS medium supplemented $5 \mathrm{mg} / 12,4-\mathrm{D}$ and $1 \mathrm{mg} / 1 \mathrm{BA}$ with in dark conditions after 4 weeks

Plate 4.3.14 Callus produced from stem explants of black pepper in half MS medium supplemented with different IAA levels (left 22mg/l IAA and right $2.2 \mathrm{mg} / \mathrm{IAA}$ in dark condition after 4 weeks. 


\section{ACKNOWLEDGEMENT}

At the very out set, I wish to express my cordial thanks to my supervisor Dr. Y.M.H.B. Yapabandara, Senior Research Officer, Natural Product Development Group, Industrial Technology Institute for his valuable guidance, continuous supervision, consistent encouragement and constructive invaluable criticism throughout the project.

I convey my sincere gratitude to my internal supervisor Dr. (Mrs) P.L. Hettiarachchi, Senior Lecturer, Department of Botany, University of Sri Jayawardanapura, Nugegoda for her stimulant guidance, supervision and consistent encouragement throughout this project and invaluable suggestions and criticisms on the manuscript.

I would like to thank National Science Foundation for providing financial assistance to carryout this project without which this task could not have been completed successfully.

My sincere thanks are also due to Dr. Jayasiri Ranatunga, Common-wealth Scientist, and West Colombia Canada, who initiated, supervised and guided enabling me to carryout this project successfully.

My sincere thanks are also due to Dr. (Mrs). Laksmi Arambewela, Manager, Natural Product Development Group, for her encouragement, guidance and for providing me with necessary facilities to carryout this project successfully

I would like to thank Dr. (Mrs.) Nandani Ediriweera, Head, Agro and Food Technology Division for providing me with necessary facilities and her kind encouragement to carryout the project successfully. 
I would like to thank Director, Industrial Technology Institute for allowing me to carryout this project in the institute.

My special thanks to Mr. K.R. Dayananda, Senior Research Officer, Natural Product Development Group for his valuable suggestions, and correction of my work during the project.

I would like to thank to Ms. Mihiri De Soyza for helping me to carryout the chemical analysis.

My special thanks are also due to all staff members of Natural Product Development Group for their continuous support through out this project.

It is pleasure to thank my colleagues Ms. Nalika Warusaperuma, Mr. Pathmasiri Ranasinghe who helped and encouraged me in various ways to complete my task successfully.

Last but not least I am greatly indebted to my wife Prasanthi Rathnayake for her moral and practical support and encouragement throughout the project work. 


\title{
Screening existing black pepper Piper nigrum L. (Family \\ Piperaceae) cultivars for superior spice value (high essential oil, oleoresin and piperine content) and their in vitro propagation
}

\section{R.M. Dharmadasa}

\begin{abstract}
Some selected local and introduced (Panniyur and Kuchin) black pepper, Piper nigrum L. cultivars from different pepper growing areas of the country were screened for physical (number of seeds per spike, length of spike, number of pinheads per spike and thousand seed weight) and chemical (oil content and composition, oleoresin content and piperine content) quality parameters in order to determine the cultivars with the best spice value. Subsequently the possibility of mass propagation of these desired cultivars using an in vitro techniques and their ability to get acclimatized under normal field conditions were tested with the view of commercializing the technique to supply pepper growers with economic cultivars.

The oil, oleoresin and piperine contents varied in both local and introduced cultivars. Among local cultivars the highest oil content (6.3\%) from Handessa-1 (Kandy district), oleoresin (21.78\%) from SMD NK (Monaragala district) and piperine (14.51\%) from Naranwela (Kandy district) were obtained. Comparatively low content of oil, oleoresin and piperine were observed in introduced cultivars. Pepper oil was analyzed using GLC (Gas Liquid xvi
\end{abstract}


Chromatography) and found that it is a mixture of about 100 different compounds. The most significant compounds identified were $\propto$-pinene, $\beta$ pinene, Limonene, Sabinene, $\propto$-phelendrine and $\beta$-Caryophyllene. The piperine content of both local and introduced cultivars seems to be similar. However, piperine contents determined by HPLC (High Performance Liquid Chromatography) method were low when compared to the direct UV (Ultra Violet) method. Results of the chemical analysis revealed that spice value was high in local cultivars when compared to the introduced cultivars.

In vitro propagation of black pepper was severely hampered by contaimination and browning. However, maintenance of mother plants in the greenhouse, by avoiding overhead watering and spraying systematic fungicide significantly reduced the contamination and browning. Browning of explants caused by a viscous jelly like exudation from the cut surface of the explants was considerably overcome by incorporation of PVP (Polyvinyl Pyrolidone) at the rate of 200 $\mathrm{mg} / \mathrm{l}$, initial culture incubation in low light and frequent transferring of explants to the fresh medium.

In vitro propagation protocol for black pepper was developed using nodal and shoot tip explants taken from greenhouse maintained mother plants. Nodal and shoot tip explants collected from actively growing pepper plants were successfully established in MS (Murasige and Skoog's 1962) medium supplemented with $2.5 \mathrm{mg} / \mathrm{BA}$ (6-Benzylaminopurine) after sterilization with $0.1 \% \mathrm{HgCl}_{2}$ for 10 minutes in a low speed shaker. 
Shoot proliferation was compared using MS medium supplemented with different growth regulators such as BA, Kinetin and 2ip (2-Isopentenyl adenine). BA was found superior over other two cytokinins tested. The suitable BA concentration was $3.5 \mathrm{mg} / 1$. A higher shoot multiplication (6.57) was observed in liquid medium than in solid medium (3.99). About 6-7 fold shoot multiplication was achieved in liquid medium within six weeks. Higher shoot multiplication was observed in some local pepper cultivars i.e. GK 49 and M4 than in introduced cultivars.

Rooting of in vitro propagated shoots from nodal and shoot explants in MS medium supplemented with $0.2 \%$ activated charcoal $(\mathrm{AC})$ both with and without IBA (3-Indolebutyric acid) were tested separately. The highest number of roots and early rooting were observed in medium with $1 \mathrm{mg} / 1 \mathrm{IBA}$ and charcoal. The rooted plantlets were transferred to pots filled with 1:1:1 coir. compost: sand and the level of successful acclimatization obtained was more than $80 \%$. The acclimatized pepper plants were transferred to normal soil and grown in the garden successfully.

Callus induction from leaf and stem explants was studied in medium containing auxin 2,4-D (2,4-Diclorophenoxy Acetic Acid) or IAA (3-Indoleacetic acid) supplemented with or without BA. Root formation was observed in some of the calli after long period of incubation but shoot regeneration from these calli was unsuccessful. 